This is the peer reviewed version of the following article:

Sorrentino R, Stephens NB, Carlson KJ, et al. The influence of mobility strategy on the modern human talus. Am J Phys Anthropol. 2019;1-14.

which has been published in final form at https://doi.org/10.1002/ajpa.23976

This article may be used for non-commercial purposes in accordance with Wiley Terms and Conditions for Use of Self-Archived Versions. 


\section{The influence of mobility strategy on the modern human talus}

Running title: The plasticity of the modern human talus

Rita Sorrentino $^{1,2}$, Nicholas B. Stephens ${ }^{3}$, Kristian J. Carlson ${ }^{4,5}$, Carla Figus ${ }^{2}$, Luca Fiorenza ${ }^{6,7}$,

Stephen Frost ${ }^{8}$, William Harcourt-Smith ${ }^{9,10,11,12}$, William Parr ${ }^{13}$, Jaap Saers ${ }^{14}$, Kevin Turley ${ }^{8}$,

Stephen Wroe ${ }^{15}$, Maria Giovanna Belcastro ${ }^{1,16}$, Timothy M. Ryan ${ }^{3}$, Stefano Benazzi ${ }^{2,17}$

${ }^{1}$ Department of Biological, Geological and Environmental Sciences, University of Bologna, Bologna 40126, Italy.

${ }^{2}$ Department of Cultural Heritage, University of Bologna, Ravenna 48121, Italy.

${ }^{3}$ Department of Anthropology, Pennsylvania State University, University Park, PA 16802, USA.

${ }^{4}$ Department of Integrative Anatomical Sciences, Keck School of Medicine, University of Southern California, Los Angeles 90089, USA.

${ }^{5}$ Evolutionary Studies Institute, University of the Witwatersrand, Palaeosciences Centre, Private Bag 3, Wits 2050 , South Africa.

${ }^{6}$ Department of Anatomy and Developmental Biology, Monash University, Clayton, VIC 3800, Australia.

${ }^{7}$ Earth Sciences, University of New England, Armidale NSW 2351 Australia.

${ }^{8}$ Department of Anthropology, University of Oregon, Eugene, OR, 97403-1218, USA.

${ }^{9}$ Graduate Center, City University of New York, New York, NY 10016, USA.

${ }^{10}$ New York Consortium in Evolutionary Primatology, New York, NY 10024, USA.

${ }^{11}$ Department of Anthropology, Lehman College, New York, NY 10468, USA.

${ }^{12}$ Division of Paleontology, American Museum of Natural History, New York, NY 10024, USA.

${ }^{13}$ Surgical and Orthopaedic Research Laboratory, Prince of Wales Hospital, University of New South Wales, Sydney 1466, Australia.

${ }^{14}$ PAVE Research Group, Department of Archaeology \& Anthropology, University of Cambridge, Pembroke Street, Cambridge CB2 3ER, United Kingdom.

${ }^{15}$ Function, Evolution and Anatomy Research Laboratory, Zoology Division, School of Environmental and Rural Science, University of New England, New South Wales 2351, Australia.

${ }^{16}$ ADES, UMR 7268 CNRS/Aix-Marseille Université/EFS, Aix-Marseille Université, CS80011, Bd Pierre Dramard, Marseille Cedex 15, 13344, France.

${ }^{17}$ Department of Human Evolution, Max Planck Institute for Evolutionary Anthropology, Leipzig 04103, Germany.

Corresponding author: Rita Sorrentino, Department of Biological, Geological and Environmental Sciences, University of Bologna, Via Selmi 3, 40126 Bologna, Italy. Phone number: +39 0544936730. Email address: rita.sorrentino2@unibo.it 


\begin{abstract}
Objectives: The primate talus is known to have a shape that varies according to differences in locomotion and substrate use. While the modern human talus is morphologically specialized for bipedal walking, relatively little is known on how its morphology varies in relation to cultural and environmental differences across time. Here we compare tali of modern human populations with different subsistence economies and lifestyles to explore how cultural practices and environmental factors influence external talar shape.
\end{abstract}

Materials and Methods: The sample consists of digital models of 142 tali from 11 archaeological and post-industrial modern human groups. Talar morphology was investigated through 3D (semi)landmark based geometric morphometric methods.

Results: Our results show distinct differences between highly mobile hunter-gatherers and more sedentary groups belonging to a mixed post-agricultural/industrial background. Hunter-gatherers exhibit a more "flexible" talar shape, everted posture and more robust and medially oriented talar neck/head, which we interpret as reflecting long-distance walking strictly performed barefoot, or wearing minimalistic footwear, along uneven ground. The talus of the post-industrial population exhibits a "stable" profile, neutral posture and less robust and orthogonally oriented talar neck/head, which we interpret as a consequence of sedentary lifestyle and use of stiff footwear.

Discussion: We suggest that talar morphological variation is related to the adoption of constraining footwear in post-industrial society, which reduces ankle range of motion. This contrasts with hunter-gatherers, where talar shape shows a more flexible profile, likely resulting from a lack of footwear while traversing uneven terrain. We conclude that modern human tali vary with differences in locomotor and cultural behavior.

Keywords: talus, Homo sapiens, subsistence strategies, footwear. 


\section{1 | Introduction}

Humans are the only obligate bipeds among extant primates. Morphologically, this shift in locomotion has led to substantial changes in the hominin skeleton, differentiating us from other extant great apes (Aiello \& Dean, 1990; Harcourt-Smith, 2010). Among all the derived anatomical features associated with this locomotor change, the human foot is among the most specialized, with the talus playing a key role in bearing body weight and maintaining stability during bipedal walking (Aiello \& Dean, 1990; Kidd, 1999; Harcourt-Smith \& Aiello, 2004). Moreover, humans have retained the ability to use their feet for other activities, such as climbing, running, striding, and limited grasping (Ingold, 2004). Overall, the locomotor strategy pursued by modern humans is highly variable between populations and environments. Consequently, human feet must adapt to these differences.

Aside from development, bone morphology is affected by differences in the loading regime, activity level and distances covered in a day (von Cramon-Taubadel, 2011; Chirchir et al., 2015; Hagihara \& Nara, 2016; Saers, Cazorla-Bak, Shaw, Stock, \& Ryan, 2016). Comparison between huntergatherers and agriculturalists indicate that the latter are characterized by less robust skeletal elements associated with a reduction in activity (Larsen, 1995; Ruff et al., 2006; Stock, 2006; Marchi, 2008; Püschel \& Benítez, 2014; Hagihara \& Nara, 2016; Saers, Ryan, \& Stock, 2019). Similarly, skeletal gracilization of internal bone structure has been observed in Holocene Homo sapiens, which is thought to be a consequence of decreased mechanical stimuli resulting in reduced apposition of bone tissue (Chirchir et al., 2015; Ryan \& Shaw, 2015; Saers et al., 2016). While most studies have investigated cross-sectional differences in cortical bone, similar reductions in trabecular bone structure have been reported for the lower and upper limbs (Stock \& Pfeiffer, 2001; Wescott, 2006; Carlson, Grine \& Pearson, 2007; Marchi, 2008; Shaw \& Stock, 2011; Püschel \& Benítez, 2014; Chirchir et al., 2015; Saers et al., 2016). Differences in the intrinsic proportions of the foot have been noted between human groups with different levels of locomotor performance. Sprinters show a shorter rearfoot, resulting in shorter moment arms (i.e., lever arm), that increases plantar flexor work and reduces energetic costs (Raichlen, Armstrong, \& Lieberman, 2011; Baxter, Novack, Werkhoven, Pennell, \& Piazza., 2012).

Aside from physiological variation, cultural and technological factors also influence the ways in which humans use their feet to interact with their environment. The most notable of these is the widespread use of stiff shoes or boots to protect feet, as in industrial societies, which contrasts with the practice of prehistoric societies and modern hunter-gatherers, who tend to walk barefoot or use 
soft footwear (Trinkaus, 2005). It has been demonstrated that prolonged use of constrictive foot coverings results in structural changes to the bones of the feet, which may manifest as pathological conditions (Hoffmann, 1905; Barnett, 1962; Trinkaus, 2005; Zipfel \& Berger, 2007;Drapeau \& Forgues-Marceau, 2019), with the forefoot showing the highest incidence of pathology (e.g. hallux valgus, reductions in bone strength, and abnormal metatarsal/metatarsophalangeal modifications). Furthermore, while the transmission of mechanical forces through the foot during the stance phase of walking seems the same in shod and unshod feet, there is a loss of pliability in plantar arches for shod individuals (Trinkaus, 2005; Kadambande, Khurana, Debnath, Bansal, \& Hariharan2006; Lieberman, 2014). Biomechanically, unshod individuals tend to have wider feet (Figure 1) that more equally distribute peak pressures during walking, which may help limit injury (D'Août, Pataky, De Clercq, \& Aerts., 2009). The foot strike patterns in runners tend to vary between shod and unshod individuals as well, with shod individuals more often striking at the heel and barefoot runners more often striking at the midfoot, thus avoiding damage to the heel from high impacts against hard substrates (Hatala, Dingwall, Wunderlich, \& Richmond, 2013; Larson, 2014; Lieberman, 2014).

It has recently been shown that hominid talar shape varies between groups characterized by different locomotor modes and substrate uses ( Turley, 2013; Turley \& Frost, 2013, 2014a; Dunn, Tocheri, Orr, \& Jungers, 2014; Knigge, Tocheri \& Orr, 2015; Turley, White, \& Frost, 2015). However, less is known about variation in talar morphology within modern humans (HarcourtSmith, 2002; Turley, 2013; Turley et al., 2015; Saers et al., 2019).

An ontogenetic study of the talocrural joint among catarrhine taxa have assessed shape variation related to behavioral, epigenetic and substrate factors (Turley \& Frost, 2014b). The study of Turley and Frost (2014b) has shown that juveniles of Pan paniscus, Pan troglodytes, and Homo sapiens have a comparable talocrural shape, while the adults of these species differ according to substrate use. This implies phenotypic plasticity of the talus in response to behavioral changes that can be genetically mediated (i.e., natural selection or genetically programmed changes), or it could not be genetically determined (i.e., activity variation within a species to comparable pressures) (Turley \& Frost, 2014b).

Furthermore, in a prior study of the talocrural joint of adult modern humans, shape differences were observed reflecting epigenetic effects of substrate and substrate modification using footwear, prompting the current study of the whole talus (Turley et al., 2015).

Considering these previous studies, we assume that talar shape may reflect the principles of bone functional adaptation, structurally adapting to different cultural practices and behavioral conditions with bone cells responding to their mechanical milieus (Ruff, Holt, \& Trinkaus, 2006). 


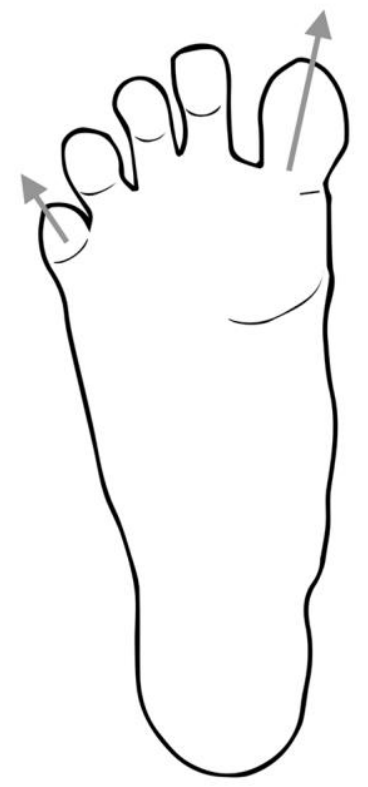

a)

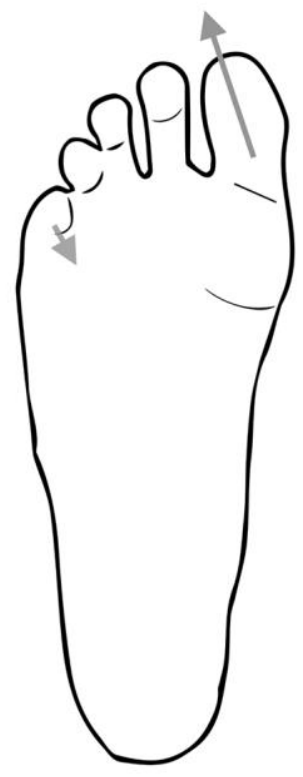

b)

Figure 1. Comparison of a) unshod and b) shod feet. An unshod foot exhibits a wider profile, flatter forefoot and toes that are spread out compared to a shod foot that exhibits a narrower forefoot, elevated arch and crowded toes.

The talus, as the rest of the foot bones, should functionally adapt to different levels of locomotory biomechanical stress (e.g., walking longer distances at greater speeds in a hunting and gathering economy) that could require a different degree of robusticity in the talus as one of the main function of the talus is bearing the body weight (Huson, 1991). Another role of the talus is to maintain stability during bipedal walking. However, different substrates may require different mechanisms (i.e., talar configuration) to achieve effective stability, for example navigating on uneven terrain versus asphalt roads may create different loading patterns. Moreover, the talus facilitates plantarand dorsal flexion, as well as inversion-eversion of the foot (Huson, 1991; Griffin, Miller, Schmitt, \& D'Août, 2015). How these ankle motions could be influenced by the use of restrictive shoes is still an open question (D’Août et al., 2009).

Here, we test the hypothesis that aspects of human talar morphology reflect variation in mobility strategy (active vs. sedentary), substrate (flat vs. uneven) and footwear (shod vs. unshod/minimally shod).

We explore talar shape variation in eleven human populations from North America, Africa and Europe, encompassing a diverse range of activity levels, subsistence strategies, and footwear use. 
Morphological data were collected by means of a 3D configuration consisting of 251 (semi)landmarks covering the entire external surface of the talus.

\section{2 | Materials and methods}

\subsection{Samples}

The sample consists of 142 tali from 11 modern human groups (Table 1). For each group, we collected information on geographical location, chronology, subsistence economies, and footwear use. Collection records (known age $>18$ years) or anthropological analysis (complete fusion of epiphyses and/or eruption of M3) was used to select only adult individuals. For commingled tali of Roccapelago, we selected only tali showing completed development of the bone and the articular facets. When present, left tali were preferred, otherwise right tali were mirrored to be included in the sample. Each talus has been evaluated to exclude the presence of pathological conditions such as osteoarthritic growth, bone anomalies and fractures.

The oldest sample includes a Late Stone Age individual (Clark Howell Omo) from Ethiopia (Parr, Chatterjee, \& Soligo, 2011) and Upper Paleolithic humans from Italy (Romito, Veneri and Villabruna) (Giacobini, 2006; Craig et al., 2010). Since they lived before the Neolithic revolution, it is assumed that their subsistence economy was based on hunting and gathering and that they were habitually barefoot or used minimalistic footwear (Trinkaus, 2005). Other hunter-gatherer populations in the sample include the Black Earth from Illinois and a Californian group (Shell Midden Cultures) from San Francisco Bay (California). The Black Earth hunter-gatherers occupied multi-season base camps (Jefferies, 2013). The Shell Midden Cultures group lived close to mud flats and estuaries and collected mollusks and fishing in the region (Breschini, 1983). The Norris Farms \#36 site (Illinois) is dated to approximately 1300 A.D., and archaeological records suggest a mixed economy based on both agriculture and foraging, with an intermediate level of mobility (Santure, Harn, \& Esarey, 1990).

Inferring footwear use in archaeological contexts is very difficult. However, the archaeological record attests to the use of sandals in the North American Southwest around ca. 9000 B.P. (Geib, 2000), whereas post-contact reports suggest that they were completely unshod (Hammond \& Rey, 1940; de Vaca, 1983). In any case, footwear used in the pre-contact period was highly unlikely to be hard soled and rigid like modern shoes. Rather, this footwear may have consisted of soft sandals and skin boots that guarantee freedom of ankle motion allowing adaptability of the foot to the substrate (Trinkaus, 2005). 
The Point Hope sample are Paleo-Inuit individuals (Alaska) with a maritime subsistence (Dumond, 2011). Ethnohistorical records suggest that they protect their feet from the cold using sealskin boots with stiff sealskin soles (Stenton, 1991; Dumond, 2011). Also, Egyptians from El Hesa had a maritime existence around the Nile River, but they also practiced agriculture and commerce. They wore sandals or soft leather boots or were unshod (Francigny, de Voogt, Kahn, \& Harcourt-Smith, 2014; AMNH Collection). Two mountain dweller groups are present in the sample. The first one consists of a Paleo Pueblo group (New Mexico) that occupied stone dwellings constructed in the Canyon de Chelly. They wore double layer woven yucca sandals (Kankainen \&Casjens, 1995). The second one consists of individuals from Roccapelago (Italy, 17th-18th century). Anthropological and historical evidence suggests gender division in occupational activities at Roccapelago. Men were mainly involved in husbandry of cattle, materials handling and transport, while women performed domestic tasks (Lugli, Brunelli, Cipriani, Bosi, Traversari, \& Gruppioni, 2017; Traversari, 2017). Generally, the activities were carried out while barefoot or minimally shod (with socks reinforced on the foot plant and on the heels). Shoes with rigid soles were worn only when going to the city or during holidays (Anselmi, 1995).

The six Nguni individuals in the sample were originally collected by Raymond A. Dart (Dart Collection, Department of Anatomical Sciences, University of the Witwatersrand, South Africa) and then, in 1926, they were donated to the Anthropological Collection of the University of Bologna managed by Prof. Fabio Frassetto. Nguni are South African people of pre-European colonization (20th century). They were herders and farmers and, despite the importance of cattle breeding in their economy, they were generally sedentary. Their clothes were made with animal skins and their traditional sandals are called "imbadada" (Gentili, 1995).

The last two groups are post-industrial individuals from Bologna (Italy) and from New York (USA). Both represent modern urban societies of the beginning of the 20th century in which the cities are surmounted by steel infrastructures and crossed by asphalt roads and concrete sidewalks. Their economy is based on different labors and specializations (agrarian, maritime, agricultural, urban). Contemporary humans are considered to have worn heavy leather shoes and boots (AMNH collection; Belcastro et al., 2017). 
Table 1. Sample examined in the present study.

\begin{tabular}{|c|c|c|c|c|c|c|}
\hline Sample & Number & Period & $\begin{array}{l}\text { Geografical } \\
\text { location }\end{array}$ & Subsistence & Typical Footwear & Collections $^{1}$ \\
\hline UP/LSA ${ }^{2}$ & 6 & Upper Paleolithic/ Late Stone Age & Italy; Ethiopia & hunter-gatherers & Unshod/soft covering & DBP/ NHMP \\
\hline Black Earth & 15 & 3000 B.C. & Illinois, USA & hunter-gatherers & Unshod/soft covering & SIU \\
\hline Californian & 9 & Shell Midden Cultures ( 1500 B.C. - 500 A.D.) & California, USA & hunter-gatherers & Unshod/soft covering & PAHM \\
\hline Norris Farms & 10 & Late Prehistoric North America (1300 A.D.) & Illinois, USA & mixed agriculture and foraging & Unshod/soft covering & ISM \\
\hline Point Hope & 8 & $\sim 1600$ - 500 B.C. & Alaska, USA & maritime subsistence & Seal Skin Boots & AMNH \\
\hline Egyptian & 7 & $\sim 600-350$ B.C. & Egypt & farmers/maritime subsistence & Thin Leather Shoes & AMNH \\
\hline Paleo Pueblo & 6 & 1000 B.C. & New Mexico, USA & mountain dwellers & Heavy Double Yucca Sandal & AMNH \\
\hline Roccapelago & 15 & 17th-18th century & Italy & mountain dwellers & Socks with reinforced soles/ shoes & SAPAB \\
\hline Nguni & 6 & 20th century & Southern Africa & Farmers & Sandals & BiGeA \\
\hline Bologna & 39 & 19th-20th century & Italy & post-industrial & Heavy Leather Shoes/Boots & BiGeA \\
\hline New York & 21 & early 20th century & New York, USA & post-industrial & Heavy Leather Shoes/Boots & NMNH \\
\hline
\end{tabular}

${ }^{1}$ DBP, Department of Biology, University of Pisa, Pisa; NHMP, The Natural History Museum, Department of Earth Sciences, London; SIU, Southern Illinois University, Carbondale; PAHM, P. A. Hearst Museum Collections, University of California, Berkeley; ISM, Illinois State Museum, Springfield; AMNH, American Museum of Natural History, New York; SAPAB, Soprintendenza Archeologia, Belle Arti e Paesaggio per la città metropolitana di Bologna e le province di Modena, Ferrara e Reggio Emilia; BiGeA, Department of Biological, Geological and Environmental Sciences, University of Bologna, Bologna; NMNH, National Museum of Natural History, Smithsonian, Washington.

${ }^{2}$ UP, Upper Paleolithic (Romito7, Romito 8, Romito 9, Veneri 2 and Villabruna); LSA, Late Stone Age (Clark Howell Omo, Ethiopia).

\section{2 | Data acquisition}

The sample was virtually acquired using a 3D laser surface scanning approach, as well as CT and microCT scanners, which has been shown to give comparable 3D models (Brzobohatá, Prokop, Horák, Jančárek, \& Velemínská, 2012). Upper Paleolithic samples from Italy (Romito 7, Romito 8, Romito 9, Veneri 2 and Villabruna) were surface scanned at the Department of Cultural Heritage (University of Bologna) with a 3D ARTEC scanner. The Late Stone Age talus of Clark Howell (Omo deposits, Ethiopia), as well as Californian, Point Hope, Egyptian, Paleo Pueblo, New York tali were acquired with a Konica Minolta Vivid 910 surface laser scanner $(\mathrm{X}: \pm 0.22 \mathrm{~mm}, \mathrm{Y}: \pm 0.16$ $\mathrm{mm}, \mathrm{Z}: \pm 0.10 \mathrm{~mm}$ ) and were processed using Geomagic Studio 8.

Roccapelago (voxel size: 0.470 x 0.470 x $0.6 \mathrm{~mm}$ ), Bologna (voxel size: 0.960 x 0.960 x $0.7 \mathrm{~mm}$ ) and Nguni (voxel size: 0.976 x 0.976 x $0.5 \mathrm{~mm}$ ) were scanned with medical CT at the Department of Diagnostic Imaging of Santa Maria delle Croci Hospital in Ravenna (Italy). 
Scans for Norris Farms, Black Earth, and a subsample of the Bologna tali were scanned using the industrial microCT (OMNI-X HD600 High-Resolution X-ray computed tomography - HRCT) at the Center for Quantitative Imaging (CQI) at the Pennsylvania State University with source energy settings $180 \mathrm{kV}, 110 \mathrm{~mA}$, and between 2800 and 4800 views (0.030-0.057 mm). Data from CT and microCT scans were reconstructed from projections and Avizo 7.1 (Visualization Science Group Inc.) was used to generate isosurfaces.

\section{3 | Geometric Morphometric analysis}

External talar surfaces were investigated through landmark-based geometric morphometric methods (GMM). A 3D-template of 251 (semi) landmarks (15 anatomical landmarks, 105 curve semilandmarks and 131 surface semilandmarks) was created in Viewbox 4 software on a specimen of the Roccapelago group (Figure 2 and Tables 2-3). The template configuration was applied to the targets, allowing the semilandmarks to slide on the curves (curves semilandmarks) and on the surface (surface semilandmarks) to minimize thin-plate spline (TPS) bending energy (Slice, 2006) between the target and the template. As a result, semilandmarks can be considered geometrically homologous (Gunz \& Mitteroecker, 2013). After Procrustes superimposition, semilandmarks were allowed to slide against recursive updates of the Procrustes consensus in R software (R Core Team, 2017) (Gunz, Mitteroecker, \& Bookstein., 2005; Mitteroecker \& Gunz, 2009). The (semi)landmark configurations were superimposed by Generalized Procrustes Analysis (GPA) (Rohlf \& Slice, 1990) using the R package "geomorph” (Adams \& Otárola-Castillo, 2013). Procrustes coordinates were subjected to Principal Component analysis (PCA) based on the group mean covariance following the function in the R package "Morpho" (Schlager, 2017) to explore shape differences among modern human tali. ANalysis Of VAriance (ANOVA) with Tukey's post hoc test was used to identify group differences along each PC. Considering only the individuals for which sex was known or anthropologically estimated $(\mathrm{N}=126)$, ANOVA was used to assess if sexual dimorphism could influence talar shape. Shape variation related to static allometry was investigated by Pearson product-moment correlation coefficients (r) of shape variables (PCs) against the natural logarithm of centroid size. Procrustes ANOVA with permutation procedures $(n=1000)$ was performed to assess group shape variation attributable to sex, typical footwear (unshod/minimally shod vs. nonrestrictive sandals/skin boots with soft soles vs. heavy leather shoes/boots), substrate (asphalt vs. 
uneven terrain vs. mountain) and mobility strategy (high vs. intermediate vs. low mobility) (Table 4).

Differences in size (i.e., centroid size, defined as the square root of the summed squared distances between each landmark to the centroid) among populations were evaluated through ANOVA Post Hoc tests and box plot analyses.

Following GPA, patterns of size and shape variation in the talus were analyzed through PCA in Procrustes form space. The form space PCA reduces shape variation in a few dimensions retaining size information by adding the logarithm of centroid size (lnCS) as an additional variable to Procrustes shape coordinates (Mitteroecker, Gunz, Bernhard, \& Schaefer, 2004; Mitteroecker, Gunz, Windhager, \& Schaefer, 2013; Klingenberg, 2016).

Data analysis were written in R software (R Core Team, 2017).
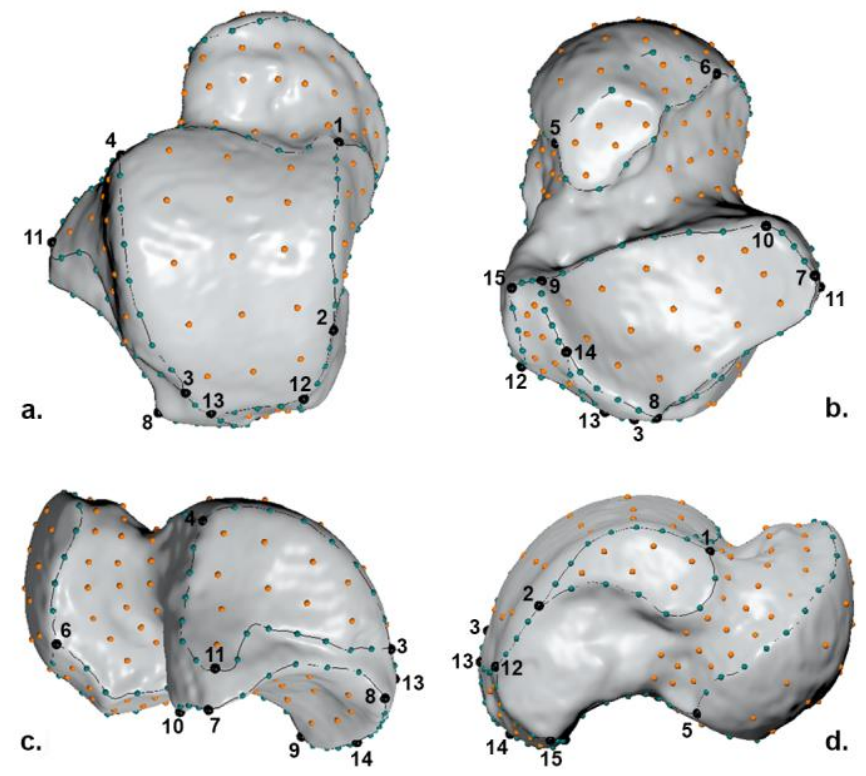

Figure 2. Talar configuration of 251 (semi)landmarks in dorsal (a), plantar (b), lateral (c) and medial (d) views. Landmarks are the numbered black spheres, while curve and surface semilandmarks are dark green and orange spheres, respectively. 
Table 2. Landmarks of talar configuration.

\begin{tabular}{lll}
\hline $\begin{array}{l}\text { Landmarks } \\
\text { Most distal lateral point of contact between the medial malleolar facet and }\end{array}$ & Type & $\begin{array}{l}\text { Label in } \\
\text { Fig. } 2\end{array}$ \\
$\begin{array}{l}\text { II trochlear surface } \\
\begin{array}{l}\text { Most proximal point of contact between the medial malleolar facet and the } \\
\text { trochlear surface }\end{array}\end{array}$ & II & 2 \\
$\begin{array}{l}\text { Most proximal point of contact between the lateral malleolar facet and the } \\
\text { trochlear surface }\end{array}$ & II & 3 \\
Most distal point of contact between the lateral malleolar facet and the & II & 4 \\
trochlear surface & & \\
Most medial point of contact between the head/navicular facet & III & 5 \\
Most lateral point on the head/navicular facet & III & 6 \\
Most lateral point on the proximal calcaneal facet & III & 7 \\
$\begin{array}{l}\text { Deepest (most dorsal) point on the proximal calcaneal facet } \\
\text { Most proximo-medial point on the proximal calcaneal facet }\end{array}$ & III & 8 \\
Most disto-lateral point on the proximal calcaneal facet & III & 9 \\
Most plantar point on the lateral malleolar facet & II & 10 \\
Flexor hallucis longus: most distal point on the medial margin & III & 11 \\
Flexor hallucis longus: most distal point on the lateral margin & III & 12 \\
Flexor hallucis longus: intersection with calcaneus curve & III & 13 \\
Flexor hallucis longus: most postero-inferior prominent point & II & 14
\end{tabular}


Table 3. Semilandmarks of talar configuration.

Semilandmarks

Semilandmarks on curve

Curve L1-L2: medial border of the trochlea corresponding to the dorsal

border of the medial malleolar facet

Curve L2-L1: inferior border of the medial malleolar facet

Curve L2-L12: postero-medial border of the trochlea 3

Curve L12-L13: posterior border of the trochlea 3

Curve L13-L3: postero-lateral border of the trochlea 1

Curve L4-L3: lateral border of the trochlea $\quad 7$

$\begin{array}{ll}\text { Curve L1-L4: anterior border of the trochlea } & 6\end{array}$

Curve L4-11: anterior border of the lateral malleolar facet 6

Curve L11-L3: inferior border of the lateral malleolar facet 7

Curve L13-L14: lateral margin of the flexor hallucis longus groove 3

Curve L12-L15: medial margin of the flexor hallucis longus groove 4

Curve L15-L9: postero-inferior margin of the flexor hallucis longus groove 2

Curve L9-L14: antero-medial border of the posterior calcaneal facet 4

Curve L14-L8: postero-medial border of the posterior calcaneal facet 4

Curve L9-L10: anterior border of the posterior calcaneal facet 6

Curve L8-L7: posterior border of the posterior calcaneal facet 5

Curve L7-L10: medial border of the posterior calcaneal facet 3

Curve L6-L5: posterior margin of the anterior-medial calcaneal facet 6

Curve L6-L5: anterior margin of the anterior-medial calcaneal facet 5

Curve L5-L6: dorsal border of the head/navicular facet 17

Semilandmarks on surface

$\begin{array}{ll}\text { Trochlea } & 15\end{array}$

Medial malleolar facet $\quad 6$

$\begin{array}{lr}\text { Lateral malleolar facet } & 10\end{array}$

$\begin{array}{ll}\text { Head/navicular facet } & 17\end{array}$

$\begin{array}{ll}\text { Neck } & 50\end{array}$

$\begin{array}{ll}\text { Anterior-medial calcaneal facet } & 10\end{array}$

$\begin{array}{lr}\text { Posterior calcaneal facet } & 15\end{array}$

Flexor hallucis longus groove $\quad 8$ 


\section{3 | Results}

Overall, our results show that talar morphology varies among modern human groups. The shape space PCA plot (Figure 3) depicts a trend in separating hunter-gatherers from early agriculturalist/post-industrial populations along PC1 (45.3\%). ANOVAs with Tukey post hoc tests (Table 5) indicate significant differences between the more mobile Upper Paleolithic/Late Stone Age group, Californian, Black Earth, and Norris Farms individuals (with generally positive PC1 scores) versus the more sedentary groups of Bologna $(\mathrm{P}<0.001)$ and New York (from $\mathrm{P}<0.005$ to $\mathrm{P}<0.001$ ) with more negative values PC1 scores. The other modern human groups (Roccapelago, Point Hope, Egyptian, Paleo Pueblo, Nguni) are intermediate, overlapping both higher and lower mobility groups, as they are probably intermediate in mobility (e.g., Norris Farms). However, most of these intermediate groups are also significantly different from post-industrial populations (from $\mathrm{P}<0.05$ to $\mathrm{P}<0.001$ ), except for the Nguni with respect to both Bologna and New York samples, as well as the Egyptians with respect to the New York sample. In a similar way, the Norris Farms, Point Hope, Egyptian, Roccapelago, and Nguni samples differ from Californian and/or Black Earth groups (Table 5).

Positive scores along PC1 (hunter-gatherers) reflect relatively shorter talar length, a trochlea that deviates slightly laterally from the midline of the talus, a mediolaterally wider anterior margin of the trochlea with an anterior extension of the medial margin, a laterally extended and curved lateral malleolar facet, a relatively more cupped medial malleolar facet that extends further anteriorly with a marked anteromedial edge for the attachment of the anterior tibiotalar ligament, an enlarged talar neck and head that are more medially oriented, and a more concave and coronally oriented posterior calcaneal facet when compared to negative scores along PC1 (sedentary groups) (Figure 3 and Supporting Information Figure S1). Principal component 2 accounts for $14.3 \%$ of shape variability with positive scores reflecting a more oval and concave posterior calcaneal facet, an antero-posteriorly longer medial trochlear edge, and a posterior extension of the medial and lateral tubercles when compared to those with negative PC2 scores. There is overlap among groups, although the North American groups tend to occupy the positive end, with Europeans and Africans (aside from Egyptians) occupying the negative end of the axis.

Procrustes ANOVA showed significant effects of shape variation due to typical footwear $(\mathrm{F}=7.72$, $\left.\mathrm{R}^{2}=0.099, \mathrm{df}=2, \mathrm{P}=0.001\right)$, substrate $\left(\mathrm{F}=6.63, \mathrm{R}^{2}=0.087, \mathrm{df}=2, \mathrm{P}=0.001\right)$ and mobility strategy $\left(\mathrm{F}=7.66, \mathrm{R}^{2}=0.099, \mathrm{df}=2, \mathrm{P}=0.001\right)\left(\mathrm{Fig}\right.$. 4). The respective $\mathrm{R}^{2}$ values indicate that both factors corresponding to typical footwear and mobility strategy are responsible for $9.9 \%$ of overall variation, whereas substrate accounts for $8.7 \%$ of overall variation. 
Sex is responsible for $1.5 \%$ of overall talar variation $\left(F=1.98, R^{2}=0.015, \mathrm{df}=1, \mathrm{P}=0.01\right)$ and ANOVA indicates no differences between sexes along PC1 and PC2 ( P > 0.05). A Pearson's correlation indicates that only PC1 is correlated with the logarithm of centroid size, i.e. static allometry $(\mathrm{r}=-0.38 ; \mathrm{P}<0.001)$. Results of centroid size on the boxplot (Supporting Information Figure S2 and Supporting Information Table S1) and an ANOVA with Tukey post hoc tests (Table 6) show that the Bologna, Upper Paleolithic/Late Stone Age, and New York samples have larger tali than those from the Black Earth group (from $\mathrm{P}<0.05$ to $\mathrm{P}<0.001$ ). The size distribution of Bologna differs also from those of Norris Farms and Egyptians ( $\mathrm{P}<0.05$, Table 6).

In the form space PCA, the first two PCs explain $77.7 \%$ of total variability (Supporting Information Figure S3). PC1 (66.5\%) accounts for variation in overall size, whereas PC2 tends to separate sedentary groups (positive scores) from more mobile modern humans (negative scores), as previously described for shape space PC1.

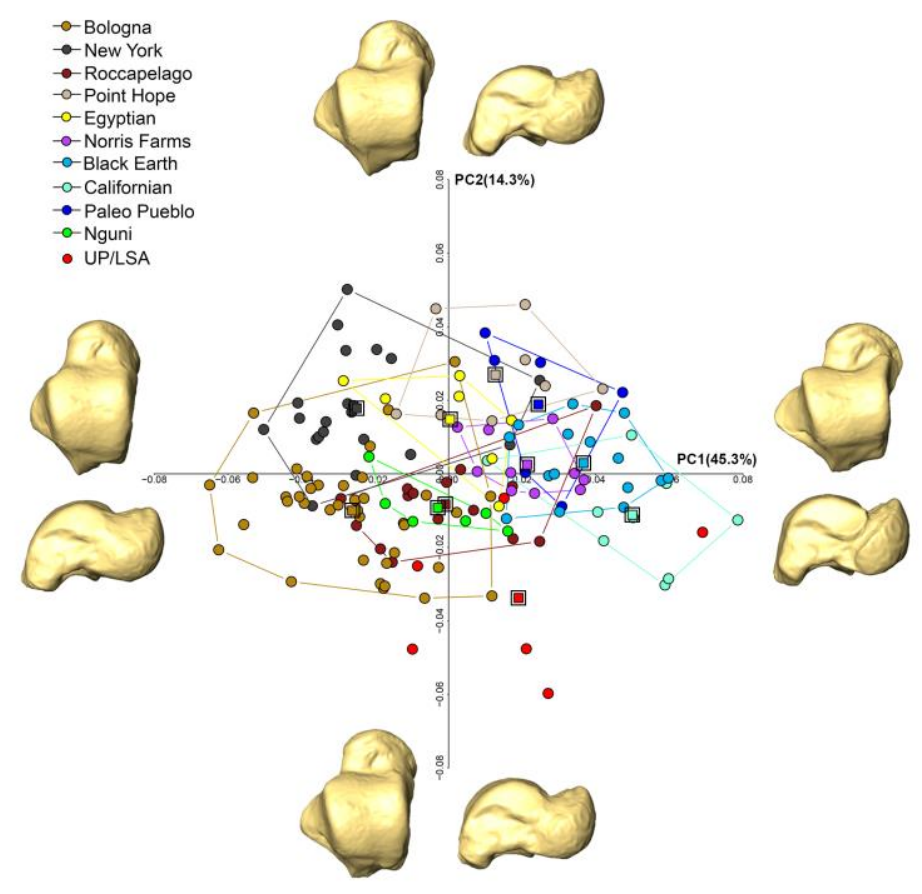

Figure 3. Shape space PCA plot and surface warps of left tali along the PC axes. Squares indicate group means. 
Table 4. Categories used for Procrustes ANOVA.

\begin{tabular}{|c|c|c|c|c|}
\hline & Footwear & Substrate & Mobility & Sex \\
\hline Sample & $\begin{array}{l}1=\text { unshod/minimally shod } \\
2=\text { non-restrictive coverings } \\
3=\text { heavy leather shoes/boots }\end{array}$ & $\begin{array}{l}1=\text { uneven terrain } \\
2=\text { asphalt } \\
3=\text { mountain }\end{array}$ & $\begin{array}{l}1=\text { high } \\
2=\text { intermediate } \\
3=\text { low }\end{array}$ & $\begin{array}{l}\mathrm{F}=\text { Female } \\
\mathrm{M}=\text { Male } \\
\mathrm{U}=\text { Unknown }\end{array}$ \\
\hline UP/LSA & 1 & 1 & 1 & $3 \mathrm{M}-1 \mathrm{~F}-2 \mathrm{U}$ \\
\hline Black Earth & 1 & 1 & 1 & $7 \mathrm{M}-8 \mathrm{~F}$ \\
\hline Californian & 1 & 1 & 1 & $4 \mathrm{M}-5 \mathrm{~F}$ \\
\hline Norris Farms & 1 & 1 & 2 & $4 \mathrm{M}-6 \mathrm{~F}$ \\
\hline Point Hope & 2 & 1 & 2 & $4 \mathrm{M}-4 \mathrm{~F}$ \\
\hline Egyptian & 2 & 1 & 2 & $4 \mathrm{M}-3 \mathrm{~F}$ \\
\hline Paleo Pueblo & 2 & 3 & 2 & $5 \mathrm{M}-2 \mathrm{~F}$ \\
\hline Roccapelago & 2 & 3 & 2 & $15 \mathrm{U}$ \\
\hline Nguni & 2 & 1 & 2 & $6 \mathrm{M}$ \\
\hline Bologna & 3 & 3 & 3 & $21 \mathrm{M}-18 \mathrm{~F}$ \\
\hline New York & 3 & 3 & 3 & $12 \mathrm{M}-9 \mathrm{~F}$ \\
\hline
\end{tabular}

Footwear

$\square$ unshod/minimally shod

$\square$ non-restrictive coverings

$\square$ heavy leather shoes/boots

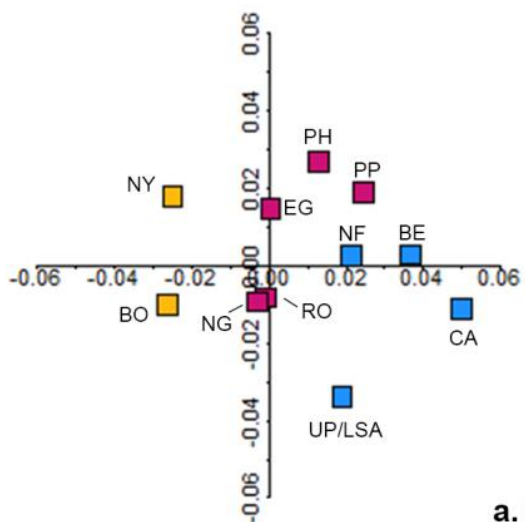

\section{Substrate}

$\square$ uneven terrain

$\square$ asphalt

mountain

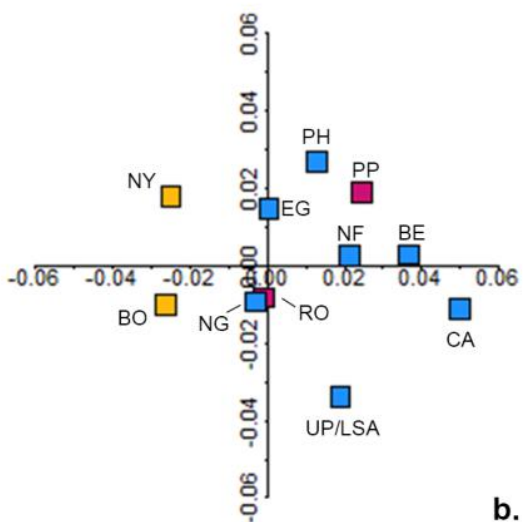

\section{Mobility}

$\square$ high

$\square$ intermediate

$\square$ low

Figure 4. Shape space PC1 vs. PC2 showing group means colored according to categories used in the Procrustes ANOVA (a. footwear; b. substrate; c. mobility). Population abbreviations include: UP/LSA, Upper Paleolithic and Late Stone Age; BE, Black Earth; CA, Californian; NF, Norris Farms; PH, Point Hope; EG, Egyptian; PP, Paleo Pueblo; RO, Roccapelago; NG, Nguni; BO, Bologna; NY, New York. 
Table 5. P-values for post hoc (ANOVA) comparisons of shape space scores of PC1 (above the diagonal) and PC2 (below the diagonal) among modern human groups.

\begin{tabular}{|c|c|c|c|c|c|c|c|c|c|c|c|}
\hline Sample $^{1}$ & UP/LSA & $\mathrm{BE}$ & CA & NF & $\mathrm{PH}$ & EG & PP & RO & NG & $\mathrm{BO}$ & NY \\
\hline UP/LSA & $x$ & 0.634 & 0.053 & 1 & 0.999 & 0.746 & 0.999 & 0.452 & 0.575 & $0.000 *$ & $0.005^{*}$ \\
\hline $\mathrm{BE}$ & 0.634 & $x$ & 0.808 & 0.598 & 0.098 & $0.001^{*}$ & 0.945 & $0.000^{*}$ & $0.000 *$ & $0.000 *$ & $0.000 *$ \\
\hline CA & 0.053 & 0.808 & $x$ & $0.030 *$ & $0.002 *$ & $0.000^{*}$ & 0.218 & $0.000^{*}$ & $0.000 *$ & $0.000 *$ & $0.000 *$ \\
\hline$N F$ & 1 & 0.598 & $0.030^{*}$ & $x$ & 0.995 & 0.403 & 0.999 & 0.100 & 0.256 & $0.000 *$ & $0.000^{*}$ \\
\hline $\mathrm{PH}$ & 0.999 & $0.098 *$ & $0.002 *$ & 0.995 & $x$ & 0.963 & 0.981 & 0.821 & 0.876 & $0.000 *$ & $0.000 *$ \\
\hline EG & 0.746 & $0.001 *$ & $0.000 *$ & 0.403 & 0.963 & $x$ & 0.382 & 1 & 0.999 & $0.019 *$ & 0.059 \\
\hline PP & 0.999 & 0.945 & 0.218 & 0.999 & 0.981 & 0.382 & $x$ & 0.134 & 0.248 & $0.000 *$ & $0.000 *$ \\
\hline RO & 0.452 & $0.000 *$ & $0.000^{*}$ & 0.100 & 0.821 & 1 & 0.134 & $x$ & 1 & $0.000 *$ & $0.000^{*}$ \\
\hline NG & 0.575 & $0.000 *$ & $0.000^{*}$ & 0.256 & 0.876 & 0.999 & 0.248 & 1 & $x$ & 0.123 & 0.242 \\
\hline BO & $0.000 *$ & $0.000 *$ & $0.000^{*}$ & $0.000 *$ & $0.000 *$ & $0.019 *$ & $0.000 *$ & $0.000^{*}$ & 0.123 & $x$ & 1 \\
\hline NY & $0.000 *$ & $0.000 *$ & $0.000^{*}$ & $0.000 *$ & $0.000 *$ & 0.059 & $0.000 *$ & $0.005^{*}$ & 0.242 & 1 & $x$ \\
\hline
\end{tabular}

${ }^{1}$ UP/LSA, Upper Paleolithic and Late Stone Age; BE, Black Earth; CA, Californian; NF, Norris Farms; PH, Point Hope; EG, Egyptian; PP, Paleo Pueblo; RO, Roccapelago; NG, Nguni; BO, Bologna; NY, New York.

*Statistically significant $(\mathrm{p}<0.05)$. 
Table 6. P-values for post hoc (ANOVA) comparisons of centroid size among modern human groups.

\begin{tabular}{|c|c|c|c|c|c|c|c|c|c|c|c|}
\hline Sample $^{1}$ & UP/LSA & $\mathrm{BE}$ & $C A$ & NF & $\mathrm{PH}$ & EG & PP & RO & NG & BO & NY \\
\hline UP/LSA & $x$ & $0.043 *$ & 0.957 & 0.397 & 0.802 & 0.313 & 0.993 & 0.865 & 0.981 & 1 & 0.999 \\
\hline $\mathrm{BE}$ & & $x$ & 0.565 & 0.997 & 0.917 & 0.999 & 0.592 & 0.482 & 0.723 & $0.000^{*}$ & $0.005^{*}$ \\
\hline$C A$ & & & $x$ & 0.989 & 0.999 & 0.958 & 1 & 1 & 1 & 0.709 & 0.988 \\
\hline NF & & & & $x$ & 0.999 & 0.999 & 0.981 & 0.992 & 0.994 & $0.031^{*}$ & 0.318 \\
\hline $\mathrm{PH}$ & & & & & $x$ & 0.998 & 0.999 & 0.999 & 0.999 & 0.355 & 0.858 \\
\hline EG & & & & & & $x$ & 0.940 & 0.964 & 0.974 & $0.037^{*}$ & 0.268 \\
\hline PP & & & & & & & $x$ & 0.999 & 1 & 0.956 & 0.999 \\
\hline RO & & & & & & & & $x$ & 1 & 0.270 & 0.898 \\
\hline NG & & & & & & & & & $x$ & 0.891 & 0.997 \\
\hline BO & & & & & & & & & & $x$ & 0.996 \\
\hline NY & & & & & & & & & & & $x$ \\
\hline
\end{tabular}

${ }^{1}$ UP/LSA, Upper Paleolithic and Late Stone Age; BE, Black Earth; CA, Californian; NF, Norris Farms; PH, Point Hope; EG, Egyptian; PP, Paleo Pueblo; RO, Roccapelago; NG, Nguni; BO, Bologna; NY, New York.

*Statistically significant $(\mathrm{p}<0.05)$.

\section{4 | Discussion}

Our results point to relevant morphological differences between hunter-gather and post-industrial populations (Figures 3-4, Supporting Information Figure S1). It is likely that these reflect biomechanical differences in response to differences in locomotor behavior. Generally, huntergatherers show relatively shorter tali when compared to individuals from post-industrial Bologna and New York groups (Figure 3 and Supporting Information Figure S1). Studies on rearfoot relative proportions report that runners tend to have shorter plantarflexor moment arms (Baxter et al., 2012) and that shorter calcaneal tubers are correlated with more efficient running (Raichlen et al., 2011). 
Although there are no controlled studies, that we are aware of, that examine how talar length is related to effective endurance running, our results suggest that there may be a relationship. Indeed, hunter-gatherers walk longer distances at greater speeds for hunting trips in comparison to ranging patterns of the sedentary post-industrial group, and this could be ultimately reflected in the talus. Further research should explore this dynamic, as it is relevant to the evolution of running capabilities in the genus Homo (Bramble \& Lieberman, 2004). Other notable shape differences exist between the various groups (Figure 3 and Supporting Information Figure S1). The post-industrial populations (Bologna and New York) show a square-shaped trochlea, whereas hunter-gatherers (especially Californian and Black Earth) are characterized by a mediolaterally expanded anterior trochlea with an anterior extension of the medial margin, as well as an anterior extension of the medial malleolar facet. The extension of both the medial malleolar surface and the medial edge of the trochlea are associated with dorsiflexion of the ankle joint (Trinkaus, 1975; Oygucu, Kurt, Ikiz, Erem, \& Davies, 1998). Similarly, talar corpora, as seen in lateral view, are relatively more dorsally convex in hunter-gatherers, allowing for a broader range of ankle excursion in the parasagittal plane (dorsal and plantar flexion) (Latimer, Ohman, \& Lovejoy 1987). Interpretation of differences in width of the anterior margin of the trochlea is more difficult. In African apes the anterior aspect of the talocrural joint is mediolaterally broad, which is thought to relate to the need for dissipating peak compressive forces associated with greater dorsiflexion during climbing (Latimer et al., 1987; DeSilva, 2009). DeSilva (2009) hypothesizes that the same would be true for hominins engaging in vertical climbing. However, Venkataraman and colleagues (Venkataraman, Kraft, DeSilva, \& Domini, 2013; Venkataraman, Kraft, \& Domini, 2013) did not observe differences between the dimensions of the anterior margin of hunter-gatherers who climb trees and those of humans from industrialized societies. Anterior mediolateral width increases also cause wedging, preventing over rotation in dorsiflexion of the talus in the talocrural joint (Barnett \& Napier, 1952). This could be related to habitual passive dorsiflexion extremes during development (for example during squatting). Due to these conflicting results, further research is needed to understand the functional significance of an expanded anterior trochlear margin.

The talocrural joint in hunter-gatherers also reflects lateral displacement of the lateral malleolar facet, a more cupped medial malleolar facet and a slightly laterally deviated trochlea. This configuration likely indicates eversion of the foot while standing and walking, and likely increased anterior wedging (Hoffmann, 1905; Barnett \& Napier, 1952) and -as expressed by the marked anteromedial edge of the medial malleolar facet in hunter-gatherers (Figure 3 and Supporting Information Figure S1)- this likely implies stress on the deltoid ligament (particularly the tibiotalar ligament), which stabilizes the ankle and restricts excessive eversion of the foot (Gibson 
\& Prieskorn, 2007; Panchani et al., 2014). The posterior extension of the medial limit of the head facet (Supporting Information Figure S1), which contacts the spring ligament during eversion, may also be linked to increased loading through an everted talus. In contrast, the configuration of the talocrural joint in post-industrial groups shows the trochlear axis more parasagittally oriented, less flared lateral malleolar facet and less cupped medial malleolar facet with unmarked anteromedial edge, likely reflecting a neutral posture and less range of motion at the ankle joint (Barnett \& Napier, 1952; Latimer et al., 1987; DeSilva, 2009; Parr, Chatterjee, \& Soligo, 2012). The talar neck and head in hunter-gatherers are more medially displaced with respect to the trochlea, while they are more orthogonally oriented in the post-industrial populations. This may be an indicator of a habitually adducted hallux as a consequence of routinely wearing rigid shoes (Hoffmann, 1905; Day \& Wood, 1968; Kidd, 1999). Scholars have shown increased medial deviation of the first metatarsal in barefoot individuals and lateral deviation of the hallux in shod feet, which may ultimately cause a valgus hallux (Hoffmann, 1905; Barnett, 1962; Trinkaus, 2005; Zipfel \& Berger, 2007) (Figure 1). Hunter-gatherers display an enlarged talar neck and more rounded, broader navicular facets. It is known that, during toe-off, transmission of body weight shifts from the talar head to the first and second metatarsals ((Griffin et al., 2015; Jashashvili, Dowdeswell, Lebrun, \& Carlson, 2015). Trinkaus (2005) showed that unshod Native Americans have more robusticity in hallucal proximal phalanges compared to habitually shod Inuit and modern Euroamericans. He found that the use of footwear reduces the role of the hallux during toe-off, dissipating the ground reaction force across the plantar aspect of the foot, ultimately resulting in decreased robusticity of hallucal phalanges. This is consistent with our results for the decreased dimensions of the talar neck and head, where the involvement of the big toe, working in conjunction with a stiff shoe, at toe-off has reduced the need for a robust talar neck and head.

Further differences are observed on the posterior portion of the talus, where the calcaneal facet appears more concave and coronally oriented in hunter-gatherers, allowing more eversion-inversion capabilities at the subtalar joint (Steele \& Bramblett, 1988; Huson, 1991). In addition, the anterior and middle calcaneal facets are separated by a ridge that, together with the posterior calcaneal facet, forms a tripod facet configuration that increases stability at the subtalar joint (Namburu, Kaavya, \& Reddy, 2017).

When taken together, these traits suggest that the tali of hunter-gatherers provided a more "flexible" shape (i.e., a shape configuration that provides greater range of motion in joint movement at the subtalar and talocrural joints), everted posture, and relatively more robust and medially oriented talar neck/head, in comparison to a more "stable" shape (i.e., a talar shape that indicates less range of motion at the subtalar and talocrural joints), neutral posture, and a more orthogonally oriented 
and less robust talar neck/ head of the tali of post-industrial people. However, it should also be noted that some differences seen in hunter-gatherers (e.g. medially extending head, trochlea-head alignment) may have an allometric origin since PC1 is correlated, although weakly, with size and the hunter-gatherer tali are (generally) smaller than the tali of post-industrial populations (Parr, Ruto, Soligo, \& Chatterjee, 2011).

Hence, overall, we suggest that morphological talar differences between hunter-gatherers and postindustrial individuals reflect differences in locomotion and load distribution related to levels of mobility, substrate and footwear use (Figure 4). This is supported by trabecular bone studies showing that lower bone volume fraction distribution in more sedentary post-industrial sample indicates reduced routine loading compared to that of highly mobile hunter-gatherers (Ryan \& Shaw, 2015; Saers et al., 2016). Particularly, a recent study of talar trabecular structure has shown that relatively mobile populations possess greater bone volume fraction associated with thicker, less widely spaced, and less interconnected trabecular structures than sedentary populations (Saers et al., 2019). These differences are associated with variation in mechanical loading resulting from different levels of mobility that ultimately echo differences in talar shape described here. In addition to greater distance travelled, talar robusticity in hunter-gatherers may reflect adaptation to uneven terrain that increases mediolateral movement, thus requiring higher stability (Carlson et al., 2007). Individuals from post-industrial societies, in contrast, who walk on packed roads or asphalt do not have to stabilize the foot over such uneven terrain, but may have to compensate for higher ground reaction forces from the stiffer substrate. A stiff shoe may be beneficial under these circumstances. Thus, the use of heavy leather shoes and boots may constrain dorsi- and plantarflexion, as well as eversion and inversion, by confining the ankle and decreasing the space in which the foot can move (i.e., remaining constricted by the shoe). All these movements are reflected in morphology of the talus of hunter-gatherers. For highly mobile and unshod individuals, the stability of the talus appears to be reinforced by the tripod configuration of the calcaneal facet (Namburu et al., 2017), as well as by the strength of medial ligaments (Panchani et al., 2014). Individuals with intermediate levels of mobility (Roccapelago, Point Hope, Egyptian, Paleo Pueblo, Nguni, Norris Farms) also adopt an intermediate footwear of non-restrictive sandals/skin boots with soft soles (Figures 3 and 4). While this style of footwear does not strongly compress the foot (Hoffmann, 1905), soft soles allow the foot to conform to the ground during running or walking. However, even if they do not walk on hard-packed surfaces (e.g., asphalt roads or concrete/packed soil), they also do not walk strictly barefoot along uneven ground. Consequently, their talar morphology reflects this intermediate level of mobility, as well as intermediate degrees of foot covering and substrate use. Indeed, the talar neck and head are relatively smaller than those of 
hunter-gatherers, while they are larger than in post-industrial populations. Additionally, the lateral and medial malleolar facets are less concave than those in more mobile people, but more concave with respect to those of sedentary populations.

However, other variables could play a role in differentiating modern human tali. Our results also point towards the relevance of allometric effects on talar shape variation. Body size inferred by the lnCS is significantly correlated $(\mathrm{P}<0.001)$ with talar shape captured by $\mathrm{PC} 1$, but variation in talar shape is not solely due to the effects of size $(\mathrm{r}=-0.38)$. Other authors who have studied talar morphological variation found that talar shape is significantly related to body size and this has been used to discern primitive traits from those influenced by body size (Parr et al., 2014; Rosas et al., 2017). However, there is not a generalized scaling rule in the talus of $H$. sapiens, and more broadly in hominoid primates, as a consequence of high intra-specific variability that could be ultimately related to differences in sex, ontogenetic trajectories and likely activity level (Parr et al., 2011a). Variation in talar morphology may also stem from ancestry, as seen in the separation of North American from European and African groups along PC2 of the shape space PCA (Figure 3). However, once again, these differences may also indicate variation in individual activities and/or be related to intraspecific population variation. Turley et al. (2015), in their study on phenotypic plasticity of the talocrural joint, noted that cliff-dwelling Native Americans (Anasazi, 1000 YBP) and 20th century New Yorkers clustered at the negative pole of the regression (shod-hard surfaces), while Native Americans from the San Francisco Bay area (55-2400 YBP) clustered at the positive pole (unshod-soft surfaces), with maritime populations of Native Americans (Inuits, $500 \mathrm{YBP}$ ) and Nile Egyptians (1500 YBP) using soft hide boots/shoes were observed to centrally cluster. Therefore, this study aligning Native American groups with both New Yorkers and Egyptians suggests that the talocrural joint is unlikely to be substantially influenced by genetic differences, at least not to a greater extent than loading similarities and/or differences. However, further studies using a broader sample are needed to assess whether other factors, such as diet, genetic affinity, clime, could potentially affect talar shape (Betti, von Cramon-Taubadel, Manica, Lycett, 2014). In conclusion, our results quantitatively demonstrate the critical functional role that the talus plays in facilitating mobility, with variation in external shape plastically responding to variation in locomotor behaviors and activity. Here we show that human talar shape varies in ways consistent with loading differences driven by variation in footwear use and terrain (i.e., highly mobile barefoot/minimal covering vs. sedentary stiff footwear). These results are relevant to interpretations of the fossil record, and may be useful in inferring the ranges of individual-specific joint movements (arthrokinematics), mobility patterns, and the behavior of extinct hominin taxa. 


\section{Acknowledgments}

This project has received funding from the European Research Council (ERC) under the European Union's Horizon 2020 research and innovation programme (grant agreement No 724046 -

SUCCESS; www.erc-success.eu). We are grateful to Francesco Feletti, Luisa Mingozzi and Denis Nicolini of the Unit of Radiology (S. Maria delle Croci Hospital of Ravenna) for providing scans for Italian collections; Natasha Johnson and Paolo Pellegatti of the P.A. Hearst Museum, UC Berkeley, for access to Native American collection; Norman Macleod for access to the NHM's Konica Minolta scanner. We thank the curators of the Museo Delle Mummie di Roccapelago for access to Roccapelago sample and Mirko Traversari for anthropological and historical information provided for this population.

\section{Conflict of Interest Statement}

The authors declare no competing interests.

\section{Data Availability Statement}

The data that support the findings of this study are available from the corresponding author upon reasonable request.

\section{Author Contributions}

RS, TMR, SB conceived and designed the experiments. RS, NBS, SF, WP, JS, KT, MGB, TMR collected the modern human sample. RS, NBS, CF, TMR carried out the microCT scan, CT scans, and the reconstruction of the digital models. RS, SB carried out the geometric morphometric analysis. RS, NBS, KJC, CF, LF, SF, WHS, WP, JS, KT, SW, MGB, TMR, SB discussed the results, wrote and edited the manuscript. 


\section{References}

Adams, D. C., \& Otárola-Castillo, E. (2013). Geomorph: an r package for the collection and analysis of geometric morphometric shape data. Methods in Ecology and Evolution, 4(4), 393399. https://doi.org/10.1111/2041-210X.12035

Aiello, L. C., \& Dean, C. (1990). An introduction to human evolutionary anatomy. San Diego, CA: Academic Press.

Anselmi, S. (1995). Contadini marchigiani del primo Ottocento: una inchiesta del Regno italico. S. Anselmi (Ed). Senigallia, IT: Sapere Nuovo.

Barnett, C. H. (1962). The normal orientation of the human hallux and the effect of footwear. Journal of Anatomy, 96(4), 489.

Barnett, C. H., \& Napier, J. R. (1952). The axis of rotation at the ankle joint in man; its influence upon the form of the talus and the mobility of the fibula. Journal of Anatomy, 86(1), 1-9.

Baxter, J. R., Novack, T. A., Werkhoven, H. Van, Pennell, D. R., \& Piazza, S. J. (2012). Ankle joint mechanics and foot proportions differ between human sprinters and non-sprinters. Proceedings of the Royal Society B: Biological Sciences, 279(1735), 2018-2024. https://doi.org/10.1098/rspb.2011.2358

Belcastro, M. G., Bonfiglioli, B., Pedrosi, M. E., Zuppello, M., Tanganelli, V., \& Mariotti, V. (2017). The history and composition of the identified human skeletal collection of the Certosa cemetery (Bologna, Italy, 19th-20th century). International Journal of Osteoarchaeology, 27(5), 912-925. https://doi.org/10.1002/oa.2605

Betti, L., von Cramon-Taubadel, N., Manica, A., \& Lycett, S. J. (2014). The interaction of neutral evolutionary processes with climatically-driven adaptive changes in the 3D shape of the human os coxae. Journal of human evolution, 73, 64-74.

Bramble, D. M., \& Lieberman, D. E. (2004). Endurance running and the evolution of Homo. Nature, 432, 345-352.

Breschini, G.S. (1983). Models of Population Movements in Central California Prehistory (doctoral dissertation). University of Washington, Washington.

Brzobohatá, H., Prokop, J., Horák, M., Jančárek, A., \& Velemínská, J. (2012). Accuracy and benefits of 3D bone surface modelling: a comparison of two methods of surface data acquisition reconstructed by laser scanning and computed tomography outputs. Collegium 
antropologicum, 36(3), 801-806.

Carlson, K. J., Grine, F. E., \& Pearson, O. M. (2007). Robusticity and sexual dimorphism in the postcranium of modern hunter-gatherers from Australia. American Journal of Physical Anthropology, 134(1), 9-23. https://doi/10.1002/ajpa.20617

Chirchir, H., Kivell, T. L., Ruff, C. B., Hublin, J., Carlson, K. J., \& Zipfel, B. (2015). Recent origin of low trabecular bone density in modern humans. Proceedings of the National Academy of Sciences, 112(2), 366-371. https://doi.org/10.1073/pnas.1411696112

Craig, O. E., Biazzo, M., Colonese, A. C., Di Giuseppe, Z., Martinez-Labarga, C., Vetro, D. L., Lelli, R., Martini, F., \& Rickards, O. 2010. Stable isotope analysis of Late Upper Palaeolithic human and faunal remains from Grotta del Romito (Cosenza), Italy. Journal of Archaeological Science, 37(10), 2504-2512. http://dx.doi.org/10.1016/j.jas.2010.05.010

von Cramon-Taubadel, N. (2011). Global human mandibular variation re fl ects differences in agricultural and hunter-gatherer subsistence strategies. Proceedings of the National Academy of Sciences, 108(49), 7-12.

D’Août, K., Pataky, T. C., De Clercq, D., \& Aerts, P. (2009). The effects of habitual footwear use: Foot shape and function in native barefoot walkers. Footwear Science, 1(2), 81-94. https://doi.org/10.1080/19424280903386411

Day, M. H. \& Wood, B. A. (1968). Functional affinities of the Olduvai hominid 8 talus. Man, 3(3), 440-455. https://doi.org/10.2307/2798879

DeSilva, J. M. (2009). Functional morphology of the ankle and the likelihood of climbing in early hominins. Proceedings of the National Academy of Sciences, 106(16), 6567-6572. https://doi.org/ 10.1073/pnas.0900270106

Drapeau, M. S., \& Forgues-Marceau, J. (2019) Metatarsal torsion in humans and footwear type. International Journal of Osteoarchaeology, 1-10.https://doi.org/10.1002/oa.2771.

Dumond, D. E. (2011). Archaeology on the Alaska Peninsula: The Northern Section: Fifty Years Onward. Eugene, OR: University of Oregon Anthropological Papers 70.

Dunn, R. H., Tocheri, M. W., Orr, C. M., \& Jungers, W. L. (2014). Ecological divergence and talar morphology in gorillas. American Journal of Physical Anthropology, 153(4), 526-541.

Francigny, V., de Voogt, A., Kahn, J., \& Harcourt-Smith, W.E.H. (2014). At the Border Between Egypt and Nubia: Skeletal Material from El Hesa Cemetery 2. J. Ancient Egypt 
Interconnections, 6: 5-10.

Geib, P. R. (2000). Sandal types and Archaic prehistory on the Colorado Plateau. American Antiquity, 65(3), 509-524.

Gentili, A. M. (1995). Il leone e il cacciatore. Storia Dell'Africa Sub-Sahariana. Roma, IT: Carocci editore.

Giacobini, G. (2006). Les sépultures du Paléolithique supérieur: la documentation italienne. Comptes Rendus Palevol, 5(1-2), 169-176

Gibson, V., \& Prieskorn, D. (2007). The Valgus Ankle. Foot and Ankle Clinics, 12(1), 15-27. https://doi.org/10.1016/j.fcl.2006.11.001

Griffin, N. L., Miller, C. E., Schmitt, D., \& D'Août, K. (2015). Understanding the evolution of the windlass mechanism of the human foot from comparative anatomy: Insights, obstacles, and future directions. American journal of physical anthropology, 156(1), 1-10.

Gunz, P., \& Mitteroecker, P. (2013). Semilandmarks: a method for quantifying curves and surfaces. Hystrix, 24(1), 103-109. https://doi.org/10.4404/hystrix-24.1-6292

Gunz, P., Mitteroecker, P., \& Bookstein, F.L. (2006). Semilandmarks in three dimensions. In: D.E. Slice (Ed.), Modern morphometrics in physical anthropology (pp. 73-98). New York, NY: Springer Science \& Business Media.

Hagihara, Y., \& Nara, T. (2016). Morphological features of the fibula in Jomon hunter-gatherers from the shell mounds of the Pacific coastal area. American Journal of Physical Anthropology, 160(4), 708-718. https://doi.org/10.1002/ajpa.23000

Hammond, G.P., \& Rey, A. (1940). Narratives of the Coronado Expedition, 1540-1542.

Harcourt-Smith, W. H. E. (2010). The first hominins and the origins of bipedalism. Evolution: Education and Outreach, 3(3), 333-340. https://doi.org/10.1007/s12052-010-0257-6

Harcourt-Smith, W. E. H., \& L. C. Aiello. (2004). Fossils, feet and the evolution of human bipedal locomotion. Journal of Anatomy, 204(5), 403-416. https://doi.org/10.1111/j.00218782.2004.00296.x

Harcourt-Smith, W. E. H. (2002). Form and function in the hominoid tarsal skeleton (doctoral dissertation). University of London, London.

Hatala, K. G., Dingwall, H. L., Wunderlich, R. E., \& Richmond, B. G. (2013). Variation in foot 
strike patterns during running among habitually barefoot populations. PLoS ONE, 8(1), 4-9. https://doi.org/10.1371/journal.pone.0052548

Hoffmann, P. (1905). Conclusions drawn from a comparative study of the feet of barefooted and shoe-wearing peoples. Journal of Bone and Joint Surgery Am., 2-3, 105-136.

Huson, A. (1991). Functional anatomy of the foot. Disorders of the foot and ankle, 1, 409-31

Ingold, T. (2004). Culture on the ground: The world perceived through the feet. Journal of Material Culture, 9(3), 315-340. https://doi.org/10.1177/1359183504046896

Jashashvili, T., Dowdeswell, M. R., Lebrun, R., \& Carlson, K. J. (2015). Cortical structure of hallucal metatarsals and locomotor adaptations in hominoids. PloS one, 10(1), e0117905.

Jefferies, R. W. (2013). The archaeology of Carrier Mills: 10,000 years in the Saline Valley of Illinois. Carbondale, IL: Southern Illinois University Press.

Kadambande, S., Khurana, A., Debnath, U., Bansal, M., \& Hariharan, K. (2006). Comparative anthropometric analysis of shod and unshod feet. Foot, 16(4), 188-191. https://doi.org/10.1016/j.foot.2006.06.001

Kankainen, K., \& Casjens, L. (1995). Treading in the Past: Sandals of the Anasazi. Salt Lake City, UT: Univ of Utah Press.

Kidd, R. (1999). Evolution of the rearfoot . A model of adaptation with evidence from the fossil record Evolution of the Rearfoot. Journal Of The American Podiatric Medical Association, 117. https://doi.org/10.7547/87507315-89-1-2

Klingenberg, C. P. (2016). Size, shape, and form: concepts of allometry in geometric morphometrics. Development Genes and Evolution, 226(3), 113-137. https://doi.org/10.1007/s00427-016-0539-2

Knigge, R. P., Tocheri, M. W., \& Orr, C. M. (2015). Three-dimensional geometric morphometric analysis of talar morphology in extant gorilla taxa from highland and lowland habitats. The Anatomical Record, 298(1), 277-290. https://doi.org/10.1002/ar.23069

Larsen, C. S. (1995). Biological changes in human populations with agriculture. Annual Review of Anthropology, 24(1), 185-213. https://doi.org/10.1146/annurev.anthro.24.1.185

Larson, P. (2014). Comparison of foot strike patterns of barefoot and minimally shod runners in a recreational road race. Journal of Sport and Health Science, 3(2), 137-142. 
https://doi.org/10.1016/j.jshs.2014.03.003

Latimer, B., Ohman, J. C., \& Lovejoy, C. O. (1987). Talocrural joint in African hominoids: implications for Australopithecus afarensis. American Journal of Physical Anthropology, 74(2), 155-175. https://doi.org/10.1002/ajpa.1330740204

Lieberman, D. E. (2014). Strike type variation among Tarahumara Indians in minimal sandals versus conventional running shoes. Journal of Sport and Health Science, 3(2), 86-94. https://doi.org/10.1016/j.jshs.2014.03.009

Lugli, F., Brunelli, D., Cipriani, A., Bosi, G., Traversari, M., \& Gruppioni, G. (2017). C4-plant foraging in Northern Italy: stable isotopes, $\mathrm{Sr} / \mathrm{Ca}$ and $\mathrm{Ba} / \mathrm{Ca}$ data of human osteological samples from Roccapelago (16th-18th centuries AD). Archaeometry, 59(6), 1119-1134. https://doi.org/10.1111/arcm.12295

Marchi, D. (2008). Relationships between lower limb cross-sectional geometry and mobility: the case of a Neolithic sample from Italy. American Journal of Physical Anthropology, 137(2), 188-200. https://doi.org/10.1002/ajpa.20855

Mitteroecker, P., \& Gunz, P. (2009). Advances in geometric morphometrics. Evolutionary Biology, $36(2), 235-247$.

Mitteroecker, P., Gunz, P., Bernhard, M., Schaefer, K., \& Bookstein, F. L. (2004). Comparison of cranial ontogenetic trajectories among great apes and humans. Journal of Human Evolution, 46(6), 679-698.

Mitteroecker, P., Gunz, P., Windhager, S., \& Schaefer, K. (2013). A brief review of shape, form, and allometry in geometric morphometrics, with applications to human facial morphology. Hystrix, 24(1), 59-66.

Namburu, B. S. P., Kaavya, H., \& Reddy, S. M. (2017). A study of morphology of talus and its calcaneal facets. International Journal of Anatomy and Research, 5(4.2), 4570-4574. https://doi.org/10.16965/ijar.2017.398

Oygucu, I. H., Kurt, M. A., Ikiz, I., Erem, T., \& Davies, D. C. (1998). Squatting facets on the neck of the talus and extensions of the trochlear surface of the talus in late Byzantine males. Journal of Anatomy, 192(2), 287-291. https://doi.org/10.1017/S0021878297003191

Panchani, P. N., Chappell, T. M., Moore, G. D., Tubbs, R. S., Shoja, M. M., Loukas, M., ... D'antoni, A. V. (2014). Anatomic study of the deltoid ligament of the ankle. Foot \& Ankle 
International, 35(9), 916-921. https://doi.org/10.1177/1071100714535766

Parr, W. C. H., Chatterjee, H. J., \& Soligo, C. (2011a). Inter- and intra-specific scaling of articular surface areas in the hominoid talus. Journal of Anatomy, 386-401. https://doi.org/10.1111/j.1469-7580.2011.01347.x

Parr, W. C. H., Ruto, A., Soligo, C., \& Chatterjee, H. J. (2011a). Allometric shape vector projection: A new method for the identification of allometric shape characters and trajectories applied to the human astragalus (talus). Journal of Theoretical Biology, 272(1), 64-71. https://doi.org/10.1016/j.jtbi.2010.11.030

Parr, W. C. H., Chatterjee, H. J., \& Soligo, C. (2012). Calculating the axes of rotation for the subtalar and talocrural joints using 3D bone reconstructions. Journal of Biomechanics, 45(6), 1103-1107. https://doi.org/10.1016/j.jbiomech.2012.01.011

Parr, W. C. H., Soligo, C., Smaers, J., Chatterjee, H. J., Ruto, A., Cornish, L., \& Wroe, S. (2014). Three-dimensional shape variation of talar surface morphology in hominoid primates. Journal of anatomy, 225(1), 42-59.

Püschel, T. A., \& Benítez, H. A. (2014). Femoral functional adaptation: a comparison between hunter gatherers and farmers using geometric morphometrics. International Journal of Morphology, 32(2), 627-633. https://doi.org/10.4067/S0717-95022014000200041

Raichlen, D. A., Armstrong, H., \& Lieberman, D. E. (2011). Calcaneus length determines running economy: Implications for endurance running performance in modern humans and Neandertals. Journal of Human Evolution, 60(3), 299-308. https://doi.org/10.1016/j.jhevol.2010.11.002

R Core Team (2017). R: A language and environment for statistical computing. Vienna, Austria: $R$ Foundation for Statistical Computing; 2017. ISBN3-900051-07-0 https://www. R-project. org.

Rohlf, F. J., \& Slice, D. (1990). Extensions of the Procrustes method for the optimal superimposition of landmarks. Systematic Biology, 39(1), 40-59.

Rosas, A., Ferrando, A., Bastir, M., García-Tabernero, A., Estalrrich, A., Huguet, R., García-Martínez, D., Pastor, J.F., \&de la Rasilla, M. 2017. Neandertal talus bones from El Sidrón site (Asturias, Spain): A 3D geometric morphometrics analysis. American journal of physical anthropology, 164(2), 394-415.

Ruff, C. B., Holt, B. M., Sládek, V., Berner, M., Murphy Jr, W. A., zur Nedden, D., ... Recheis, W. 
(2006). Body size, body proportions, and mobility in the Tyrolean "Iceman." Journal of Human Evolution, 51(1), 91-101.

Ruff, C., Holt, B., \& Trinkaus, E. (2006). Who's afraid of the big bad Wolff? "Wolff's law" and bone functional adaptation. American Journal of Physical Anthropology, 129(4), 484-498.

Ryan, T. M., \& Shaw, C. N. (2015). Gracility of the modern Homo sapiens skeleton is the result of decreased biomechanical loading. Proceedings of the National Academy of Sciences, 112(2), 372-377. https://doi.org/10.1073/pnas.1418646112

Saers, J. P.P., Ryan, T. M., Stock, J. T. (2019). Trabecular bone functional adaptation and sexual dimorphism in the human foot. American Journal of Physical Anthropology, 168(1), 154-169. https://doi.org/DOI: 10.1002/ajpa.23732

Saers, J. P. P., Cazorla-Bak, Y., Shaw, C. N., Stock, J. T., \& Ryan, T. M. (2016). Trabecular bone structural variation throughout the human lower limb. Journal of Human Evolution, 97, 97108. https://doi.org/10.1016/j.jhevol.2016.05.012

Santure, S. K., Harn, A. D., \& Esarey, D. (1990). Archaeological investigations at the Morton Village and Norris Farms 36 cemetery. Springfield, IL: Illinois State Museum.

Schlager, S. (2017). Morpho and Rvcg - shape analysis in R: R-Packages for geometric morphometrics, shape analysis and surface manipulations. In Statistical Shape and Deformation Analysis: Methods, Implementation and Applications (1st ed.). https://doi.org/10.1016/B978-0-12-810493-4.00011-0

Shaw, C. N., \& Ryan, T. M. (2012). Does skeletal anatomy reflect adaptation to locomotor patterns? cortical and trabecular architecture in human and nonhuman anthropoids. American Journal of Physical Anthropology, 147(2), 187-200. https://doi.org/10.1002/ajpa.21635

Shaw, C. N., \& Stock, J. T. (2011). The influence of body proportions on femoral and tibial midshaft shape in hunter-gatherers. American Journal of Physical Anthropology, 144(1), 2229. https://doi.org/10.1002/ajpa.21363

Slice, D. E. (2006). Modern morphometrics in physical anthropology. R. H. Tuttle (Ed.). New York, NY: Springer Science \& Business Media.

Steele, D. G., \& Bramblett, C. A. (1988). The anatomy and biology of the human skeleton. Texas A\&M University Press.

Stenton, D. R. (1991). The adaptive significance of caribou winter clothing for arctic hunter- 
gatherers. Etudes inuit, 15(1), 3-28.

Stock, J. T. (2006). Hunter-gatherer postcranial robusticity relative to patterns of mobility, climatic adaptation, and selection for tissue economy. American Journal of Physical Anthropology, 131(2), 194-204. https://doi.org/10.1002/ajpa.20398

Stock, J., \& Pfeiffer, S. (2001). Linking structural variability in long bone diaphyses to habitual behaviors: foragers from the southern African Later Stone Age and the Andaman Islands. American Journal of Physical Anthropology, 115(4), 337-348. https://doi.org/10.1002/ajpa.1090

Traversari, M. (2017). Ricostruzione del profilo bioculturale e biodemografico di una piccola comunita'montana del XVI-XVIII secolo attraverso i dati archeoantropologici e documentari: il caso degli inumati di Roccapelago (Modena) (doctoral dissertation). Alma Mater Studiorum Università di Bologna (alma), Bologna. https://doi.org/10.6092/unibo/amsdottorato/8205

Trinkaus, E. (2005). Anatomical evidence for the antiquity of human footwear use. Journal of Archaeological Science, 32, 1515-1526. https://doi.org/10.1016/j.jas.2007.12.002

Trinkaus, E. (1975). Squatting among the Neandertals: a problem in the behavioral interpretation of skeletal morphology. Journal of archaeological science, 2(4), 327-351. https://doi.org/ 10.1016/0305-4403(75)90005-9

Turley, K., White, F.J., Frost, S. R. (2015). Phenotypic plasticity: the impact of habitat and behavior ( substrate use ) on adult talo-crural appositional articular joint shape both between and within closely related hominoid species. Human Evolution, 30(1-2), 49-67. https://doi.org/10.14673/HE201512002

Turley, K., \& Frost, S. R. (2014a). The Appositional Articular Morphology of the Talo-crural Joint: The Influence of Substrate Use on Joint Shape. The Anatomical Record, 297(4), 618-629. https://doi.org/10.1002/ar.22879

Turley, K., \& Frost, S. R. (2014b). The ontogeny of talo-crural appositional articular morphology among catarrhine taxa: Adult shape reflects substrate use. American journal of physical anthropology, 154(3), 447-458.

Turley, K., \& Frost, S. R. (2013a). The shape and presentation of the catarrhine talus: a geometric morphometric analysis. The Anatomical Record, 296(6), 877-890.

https://doi.org/10.1002/ar.22696 
Turley, K. (2013b). Ankle morphology: interface of genetics, ontogeny and use (doctoral dissertation). University of Oregon, Oregon.

de Vaca, A. N. C. (1983). Cabeza de Vaca's Adventures in the unknown interior of America. Albuquerque, ABQ: University of New Mexico Press.

Venkataraman, V. V., Kraft, T. S., DeSilva, J. M., \& Dominy, N. J. (2013). Phenotypic plasticity of climbing-related traits in the ankle joint of great apes and rainforest hunter-gatherers. Human Biology, 85(1-3), 309-328. https://doi.org/10.3378/027.085.0315

Venkataraman, V. V, Kraft, T. S., \& Dominy, N. J. (2013). Tree climbing and human evolution. Proceedings of the national academy of sciences, 110(4), 1237-1242. https://doi.org/10.1073/pnas.1208717110

Wescott, D. J. (2006). Effect of mobility on femur midshaft external shape and robusticity. American Journal of Physical Anthropology, 130(2), 201-213.

Zipfel, B., \& Berger, L. R. (2007). Shod versus unshod: the emergence of forefoot pathology in modern humans? Foot, 17(4), 205-213. https://doi.org/10.1016/j.foot.2007.06.002 


\section{Figure Legends}

Figure 1. Comparison of a) unshod and b) shod feet. An unshod foot exhibits a wider profile, flatter forefoot and toes that are spread out compared to a shod foot that exhibits a narrower forefoot, elevated arch and crowded toes.

Figure 2. Talar configuration of 251 (semi)landmarks in dorsal (a), plantar (b), lateral (c) and medial (d) views. Landmarks are the numbered black spheres, while curve and surface semilandmarks are dark green and orange spheres, respectively.

Figure 3. Shape space PCA plot and surface warps of left tali along the PC axes. Squares indicate group means.

Figure 4. Shape space PC1 vs. PC2 showing group means colored according to categories used in the Procrustes ANOVA (a. footwear; b. substrate; c. mobility). Population abbreviations include: UP/LSA, Upper Paleolithic and Late Stone Age; BE, Black Earth; CA, Californian; NF, Norris Farms; PH, Point Hope; EG, Egyptian; PP, Paleo Pueblo; RO, Roccapelago; NG, Nguni; BO, Bologna; NY, New York. 